\title{
Article \\ High Anisotropic Thermal Conductivity, Long Durability Form-Stable Phase Change Composite Enhanced by a Carbon Fiber Network Structure
}

\author{
Kaixin Dong ${ }^{1}$, Nan Sheng ${ }^{2}$, Deqiu Zou ${ }^{3}$, Cheng Wang ${ }^{4}$, Xuemei $\mathrm{Yi}^{5}$ and Takahiro Nomura ${ }^{6, *}$ \\ 1 Graduate School of Engineering, Hokkaido University, Kita 13 Nishi 8, Kita-ku, Sapporo, \\ Hokkaido 060-8628, Japan; kaixindong@eis.hokudai.ac.jp \\ 2 School of Electrical and Power Engineering, China University of Mining and Technology, \\ Xuzhou 221116, China; snym@cumt.edu.cn \\ 3 Faculty of Maritime and Transportation, Ningbo University, Ningbo 315211, China; zoudeqiu@nbu.edu.cn \\ 4 Jiangsu Provincial Key Laboratory of Oil \& Gas Storage and Transportation Technology, \\ Changzhou University, Changzhou 213016, China; chwang@cczu.edu.cn \\ 5 College of Mechanical and Electronic Engineering, Northwest A\&F University, Xinong Road 22, Yangling, \\ Shaanxi 712100, China; xuemei_yi@nwsuaf.edu.cn \\ 6 Faculty of Engineering, Hokkaido University, Kita 13 Nishi 8, Kita-ku, Sapporo, Hokkaido 060-8628, Japan \\ * Correspondence: nms-tropy@eng.hokudai.ac.jp; Tel.: +81-11-706-6842; Fax: +81-11-706-6849
}

check for

updates

Citation: Dong, K.; Sheng, N.; Zou, D.; Wang, C.; Yi, X.; Nomura, T. High Anisotropic Thermal Conductivity, Long Durability Form-Stable Phase Change Composite Enhanced by a Carbon Fiber Network Structure.

Crystals 2021, 11, 230.

https://doi.org/10.3390/

cryst 11030230

Academic Editor: Pavel Lukáč

Received: 5 February 2021

Accepted: 23 February 2021

Published: 25 February 2021

Publisher's Note: MDPI stays neutral with regard to jurisdictional claims in published maps and institutional affiliations.

Copyright: (c) 2021 by the authors. Licensee MDPI, Basel, Switzerland. This article is an open access article distributed under the terms and conditions of the Creative Commons Attribution (CC BY) license (https:/ / creativecommons.org/licenses/by/ $4.0 /)$.
Abstract: To address the drawback of low thermal conductivity of conventional organic phase change materials (PCMs), a paraffin-wax-based phase change composite (PCC) was assembled via a vacuum impregnation method, using a new type of carbon fiber network material as the supporting matrix. The carbon fiber sheet (CFS) material exhibited a network structure comprising high-thermal-conductivity carbon fibers, beneficial for enhancing the heat transfer properties of the PCC. The sheet-shaped carbon fiber material was stacked and compressed, and then impregnated with the liquid paraffin wax PCM to form the composite. The thermal conductivity, durability, shape stability, chemical stability, and heat storage characteristics of the PCC specimen were carefully analyzed. The maximum thermal conductivity of the PCC was $11.68 \mathrm{~W} \cdot \mathrm{m}^{-1} \cdot \mathrm{K}^{-1}(4670 \%$ compared to that of pure paraffin) in the radial direction, and $0.93 \mathrm{~W} \cdot \mathrm{m}^{-1} \cdot \mathrm{K}^{-1}$ in the axial direction of the sample, with $17.44 \mathrm{vol} \%$ of added CFS. The thermal conductivity retention rate after 200 thermal cycles was $78.6 \%$. The PCC also displayed good stability in terms of chemical structure, shape, and heat storage ability. This study offers insights and a possible strategy for the development of anisotropic high-thermal-conductivity PCCs for potential applications in latent heat storage systems.

Keywords: latent heat storage; PCM; thermal conductivity; composite

\section{Introduction}

Energy consumption management is becoming increasingly important as energy demand increases. In 2019, the percentage of fossil-fuel-derived energy utilized as primary energy amounted to $84 \%$, as reported by British Petroleum (2019). The consumption of non-renewable fossil fuels has led to numerous environmental problems, with increasing $\mathrm{CO}_{2}$ emissions being especially distressing. A reduction in fossil fuel consumption can be realized by improving energy efficiency [1].

The recovery of waste energy is considered an effective strategy for improving energy efficiency [2]. Phase change materials (PCMs) have received increasing attention in the field of latent heat storage (LHS) technology due to their potential application in the recovery of thermal energy waste. The study of PCMs for low-temperature waste heat recovery has generally been centered on organic PCMs, such as paraffin wax, sugar alcohols, and fatty acids, which have the advantages of high heat storage capacity, high chemical stability, high thermal reliability, nontoxicity, corrosion and flame resistance, and low 
cost. However, the direct utilization of organic PCMs is limited by a critical disadvantage; the heat transfer capability of organic materials is invariably inadequate, and the thermal conductivity of organic PCMs is usually lower than $0.5 \mathrm{~W} \cdot \mathrm{m}^{-1} \cdot \mathrm{K}^{-1}$, which is lower than the thermal conductivity of water $\left(0.62 \mathrm{~W} \cdot \mathrm{m}^{-1} \cdot \mathrm{K}^{-1}\right)$ at room temperature. Such a low thermal conductivity leads to inadequate heat storage and sluggish heat release rates in LHS systems. Prerequisite characteristics for the practical application of PCMs include a high heat exchange rate, long durability, and shape stability.

Therefore, enhancing the thermal conductivity of PCMs is necessary for the development of practical PCM-based LHS systems. The development of phase change composites (PCCs) using pure PCMs and various functional additives has proven to be the most fruitful strategy for PCM performance enhancement. Numerous materials have been used as additives to enhance the heat transfer performance of PCMs, such as carbon materials (including carbon nanotubes [3], carbon fibers [4], graphite [5], graphene [6]), metal particles and foams ( $\mathrm{Cu}[7], \mathrm{Ni}[8]$, and $\mathrm{Al}[9,10])$, and compounds with favorable thermal conductivity properties (BN [11], Alumina [12], Silica [13]). Burger et al. reviewed the thermal conductivity properties of composites [14] and summarized the mechanisms by which these properties are enhanced by the filler material. The structure and nature of the filler determines the result of thermal conductivity enhancement. Fillers with an elongated shape and a high aspect ratio result in higher thermal conductivities than those attained with spherical particle fillers. This is because contact thermal resistance occurs at the filler/matrix interface, and the interface area is smaller for elongated fillers than for spherical particles. Park et al. [15] demonstrated that long MWCNTs $\left(55 \mathrm{~W} \cdot \mathrm{m}^{-1} \cdot \mathrm{K}^{-1}\right.$ at $60 \% \mathrm{wt}$.) enhanced thermal conductivity to a significantly higher extent than short MWCNTs $\left(20 \mathrm{~W} \cdot \mathrm{m}^{-1} \cdot \mathrm{K}^{-1}\right.$ at $60 \% \mathrm{wt}$.) in epoxy composites. Furthermore, forming a network structure with thermally conductive fillers can result in a higher degree of enhancement than that achieved by adding randomly dispersed filler. Nomura et al. [16] proved that the percolated network structure was superior to randomly dispersed fillers in terms of increasing thermal conductivity. Numerous previous studies have likewise proven this theory. [17,18]. Jiang et al. [19] fabricated a carbon-bonded carbon fiber network-based composite. Using resin and carbon fibers to fabricate a porous network initially and then impregnating paraffin into the network structure. The thermal conductivity of the composite reached $13.8 \mathrm{~W} \cdot \mathrm{m}^{-1} \cdot \mathrm{K}^{-1}, 57$ times higher than that of pure paraffin. In the studies reviewed above, a network structure of carbon fiber in the composite was formed, and the PCM thermal conductivity was improved to a high value.

The majority of previous studies have focused on enhancing the thermal conductivity and shape stability of PCMs, and many have also centered on improving the durability of PCCs, latent heat, and shape stability. However, only a few reports have focused on the durability of enhanced PCMs; the high thermal conductivity of the enhanced PCM must also be durable for practical utilization. In this study, we report the fabrication of a PCC using long carbon fiber networks to enhance the thermal conductivity, durability, and shape-stability of paraffin wax PCM. The PCC was fabricated via a vacuum impregnation method, and the carbon fiber sheet material comprises long carbon fibers and binders and was generated by traditional papermaking technology. The microstructure, thermal conductivity, durability, shape-stability, chemical stability, and heat storage performance of the PCC were carefully investigated.

\section{Experimental}

\subsection{Materials}

Paraffin wax (PW) was used as the PCM in this study. Paraffin wax is widely utilized for low-temperature LHS systems, owing to its suitable melting point, high latent heat, and low cost. A high-thermal-conductivity carbon fiber sheet developed by Azumi Co., Ltd. was used to enhance the thermal performance of the paraffin PCM. The elementary properties of these two raw materials are listed in Table 1. 
Table 1. Basic properties of raw materials.

\begin{tabular}{ccccc}
\hline Material & $\begin{array}{c}\text { Density } \\
{\left[\mathbf{k g} \cdot \mathbf{m}^{-\mathbf{3}}\right]}\end{array}$ & $\begin{array}{c}\text { Latent Heat } \\
{\left[\mathbf{k J} \cdot \mathbf{k g}^{-\mathbf{1}}\right]}\end{array}$ & $\begin{array}{c}\text { Specific Heat } \\
{\left[\mathbf{k J} \cdot \mathbf{k g}^{-1} \cdot \mathbf{K}^{-\mathbf{1}}\right]}\end{array}$ & $\begin{array}{c}\text { Thermal Conductivity } \\
{\left[\mathbf{W} \cdot \mathbf{m}^{-\mathbf{1}} \cdot \mathbf{K}^{-\mathbf{1}}\right]}\end{array}$ \\
\hline Paraffin wax & 0.90 & 220 & 2.259 & 0.24 \\
\hline Carbon fiber sheet & 2.09 & - & 0.72 & $>900$ \\
\hline
\end{tabular}

\subsection{Experimental Method}

The PW/CFS phase change composite was fabricated via the vacuum impregnation method, as shown in Figure 1. The carbon fiber sheets were cut into $10 \mathrm{~cm} \times 10 \mathrm{~cm}$ pieces. Then, 20, 22, 24, and 26 pieces of CFSs were compressed and fixed by two aluminum plates to increase the volume fraction of CFS in the composite. Then, the fixed samples were impregnated with liquid paraffin at $100{ }^{\circ} \mathrm{C}$ in a vacuum oven for $3 \mathrm{~h}$. The impregnated samples were cut along the vertical and horizontal directions and polished into disks (diameter $=1 \mathrm{~cm}$, height $=1-3 \mathrm{~mm}$ ) for thermal conductivity measurements.

\section{$1 \mathrm{~cm} \times 1 \mathrm{~cm}$ CFS}
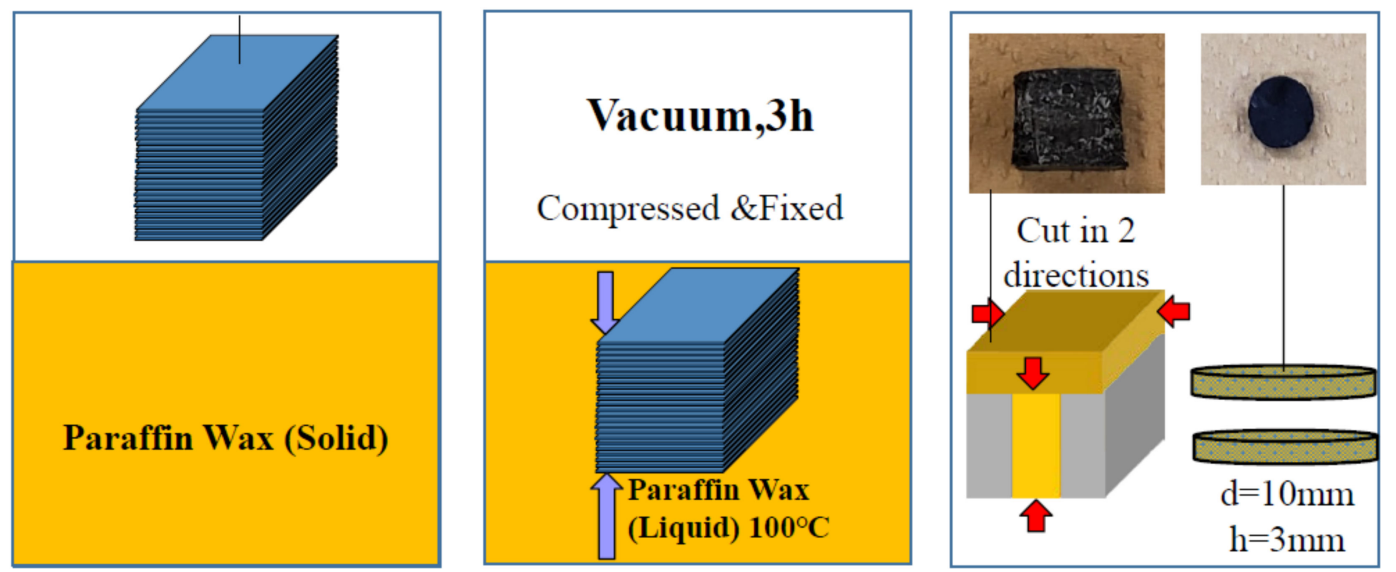

Figure 1. Schematic representation for fabricating a phase change composite by the vacuum impregnation method along with the sample preparation for laser flash measurements.

Additionally, a durability cycling test and shape-stability test were performed to investigate the performance of the PCC samples after long-term repetitive use. The durability test was performed using a motive furnace device. The sample was heated at $100{ }^{\circ} \mathrm{C}$ for $20 \mathrm{~min}$ and cooled at room temperature $\left(25^{\circ} \mathrm{C}\right)$ for $40 \mathrm{~min}$ to accomplish a complete melting-solidification cycle. The samples were tested over 20 and 200 cycles. After the durability test, the thermal characteristics and properties of the PCC were analyzed. The shape stability test of the PCC was conducted by heating paraffin and PCC in an oven at $100{ }^{\circ} \mathrm{C}$ for $20 \mathrm{~min}$; by comparing the two samples during melting, the shape stability and leakage prevention capabilities of the PCC could be inferred.

\subsection{Characterization}

The thermal diffusivity $(\alpha)$ of the PCC fabricated in this study was measured using an ULVAC TC-7000 laser flash system (ULVAC, Inc. Kanagawa, Japan), known to be an accurate and reliable method. The PCC samples were cut and polished into disks (diameter $=10 \mathrm{~mm}$, height $=2 \mathrm{~mm}$ ), and every sample was analyzed in both vertical and horizontal directions. The accuracy of thermal diffusivity measurement was $\pm 5.0 \%$. The measurement was repeated 5 times for each specimen.

The thermal conductivity $(\mathrm{k})$ of materials can be calculated as

$$
\mathrm{k}=\alpha \cdot \rho \cdot \mathrm{Cp}
$$


where $\alpha$ is the thermal diffusivity of the PCC directly measured by laser flash, $\rho$ is the density of the PCC measured by an ultrapycnometer (Quantachrome Instruments, Ultrapycnometer 1000, with an accuracy of $\pm 0.01 \%), \mathrm{Cp}$ is the specific heat of the PCC calculated using the volume fraction of each component and the specific heats of paraffin and CFS.

The latent heat and thermal characteristics of the PCCs and pure PCM were inferred from differential scanning calorimetry (DSC, METTLER TOLEDO DSC823) measurements, conducted at a heating/cooling rate of $10^{\circ} \mathrm{C} / \mathrm{min}$. The composition of PCM and PCC specimens were measured by X-ray diffraction (XRD, Rigaku Miniflex600, Tokyo, Japan, D/teX Ultra2, $\mathrm{Cu} \mathrm{K} \alpha$ ).

\section{Results and Discussion}

\subsection{Effective Thermal Conductivity of the PCC}

The low thermal conductivity of conventional paraffin PCM is the principal drawback restricting the practical utilization of latent heat storage systems. The thermal conductivity of paraffin wax is approximately $0.25 \mathrm{~W} \cdot \mathrm{m}^{-1} \cdot \mathrm{K}^{-1}$. Thus, we utilized a new carbon-based network to enhance the thermal conductivity of paraffin wax. The thermal conductivities of the PCC samples measured in the radial and axial directions are shown in Figure 2. The measured thermal conductivities of the composite samples from the radial direction are $7.30,9.92,10.82$, and $11.68 \mathrm{~W} \cdot \mathrm{m}^{-1} \cdot \mathrm{K}^{-1}$ corresponding to $13.49 \%, 14.70 \%, 16.47 \%$, and $17.44 \%$ volume fraction of CFS added, respectively. The thermal conductivity of the paraffin PCM was enhanced by up to 46.7-fold compared to that of pure paraffin. The thermal conductivities of the PCCs in the axial direction were only $0.75,0.74,0.87$, and $0.93 \mathrm{~W} \cdot \mathrm{m}^{-1} \cdot \mathrm{K}^{-1}$. The highly crystalline carbon fiber markedly enhanced thermal conductivity even at low volume fractions; the PCC also exhibited strong anisotropy in thermal conductivity after enhancement, and the thermal conductivity in the axial direction was significantly lower than that in the radial direction.

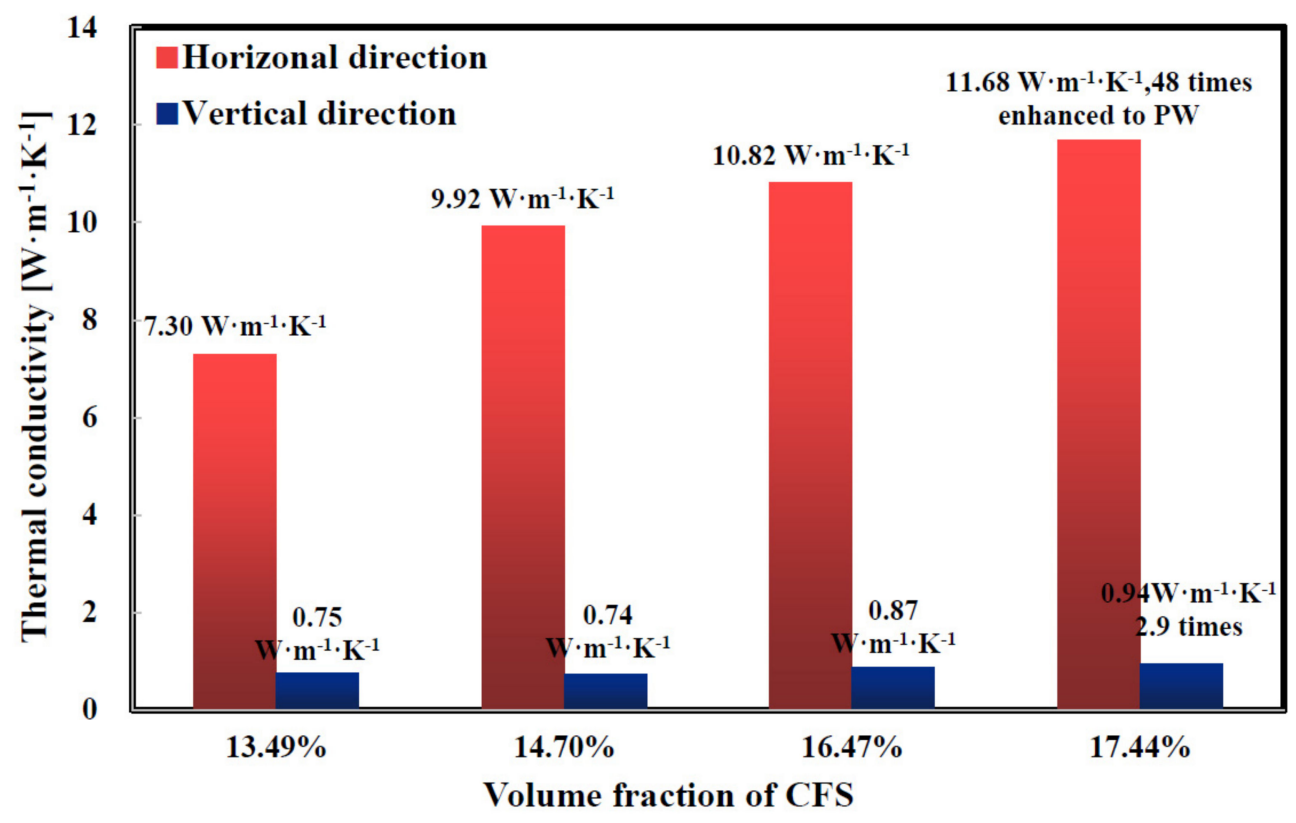

Figure 2. Thermal conductivity of paraffin wax/carbon fiber sheet (PW/CFS) composites in vertical direction and horizonal direction.

The SEM images of the CFS and PCC surfaces and cross-sections are shown in Figure 3. In Figure $3 \mathrm{a}, \mathrm{b}$, a network structure comprising long carbon fibers can be clearly observed; this type of continuous network structure contributes to enhancing the thermal conductivity of the PCM. After impregnation, the spaces and pores among the carbon fibers were filled 
by paraffin, as seen in Figure 3c,d, with no visible pores remaining after impregnation (low porosity provided less pores, and gas pores were detrimental to heat transfer because of the low thermal conductivity of the gas). The majority of the carbon fibers were aligned only on the horizonal plane of the CFS; after impregnation and polishing, carbon fibers were still located on the horizontal plane and no fibers were aligned along the vertical direction. This anisotropic alignment of carbon fibers explains the appreciable difference between the thermal conductivities in the vertical and horizontal directions of the PCC. In practical applications of the LHS system (especially industrial waste heat recovery), anisotropic thermal conductivity of the PCC could be advantageous for achieving directed heat transfer and reducing heat loss in the unwanted direction. Directed high-speed heat transfer during system charging and discharging can improve the heat recovery efficiency, thereby reducing heat loss to the environment [20].
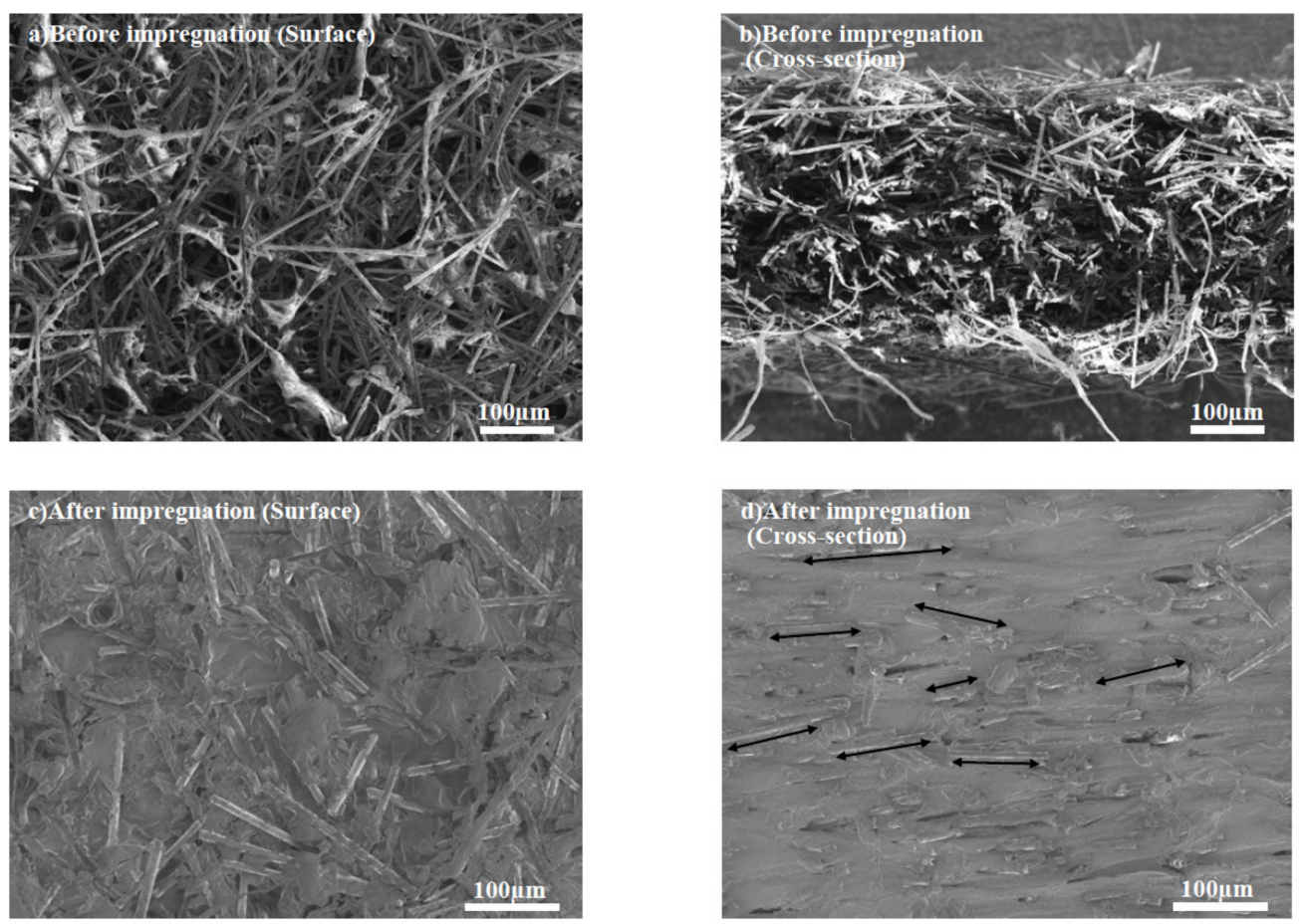

Figure 3. SEM images of (a) CFS surface before impregnation, (b) CFS cross-section before impregnation, (c) phase change composite (PCC) surface after impregnation, (d) PCC cross-section after impregnation.

\subsection{Durability and Form Stability of the PCC}

To operate under practical application conditions, the cyclability of latent heat systems needs to be long. Therefore, the fabricated PCC should be durable; we tested the durability of our PCC samples using a motive-furnace-based heating system. Twenty and 200 meltingsolidification thermal cycles were completed, and the thermal conductivities of the samples were measured after the durability test. The results are shown in Figure 4. After 20 and 200 thermal cycles, the PCC samples (horizontal direction) retained $85.9 \%$ ( 20 cycles) and $78.6 \%$ (200 cycles) of their thermal conductivity. This result indicates that the carbon fiber network in the CFS material remains stable after several thermal cycles; the binders in the CFS are stable at the working temperature of the PCC and can resist the expanding force of the melting paraffin PCM. We believe that leakage during PCM melting and the increase in contact thermal resistance in the CFS are the two chief reasons for PCC thermal conductivity degradation. PCM leakage forms small air pores with extremely low thermal conductivity in the PCC, and the binders in the CFS may undergo some degradation during heating, affecting the structure of the carbon fiber network. 


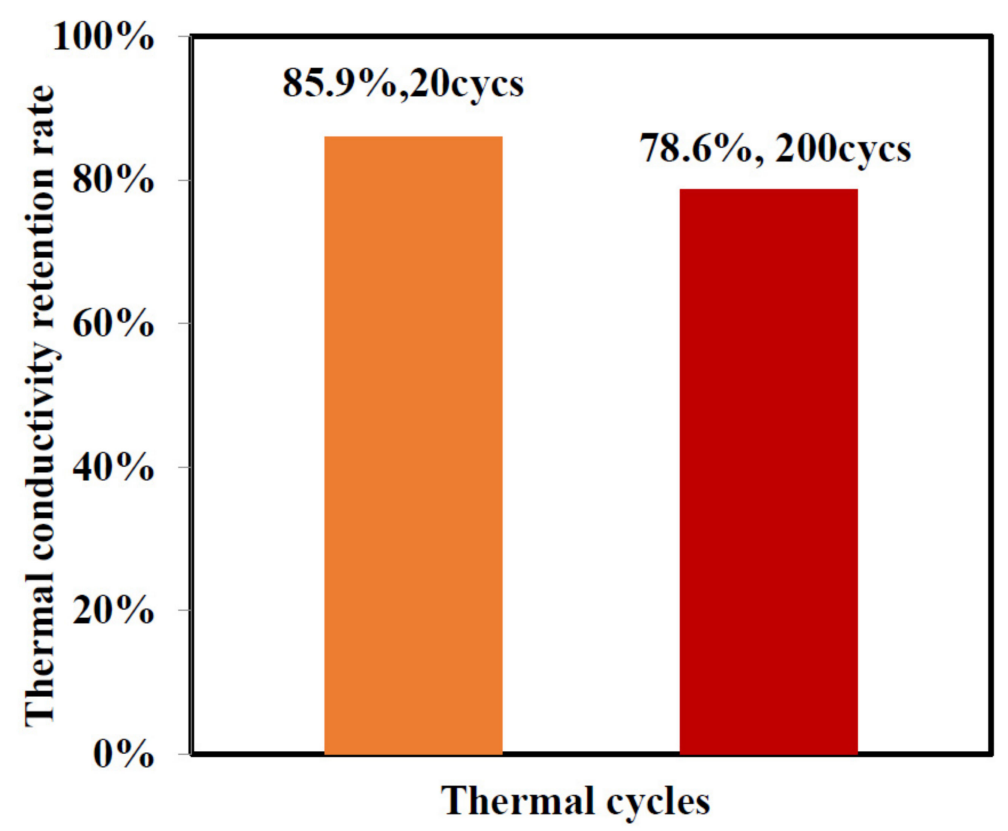

Figure 4. Thermal conductivity retention rate of the PCC after 20 and 200 thermal cycles.

The form-stability of the PCC was investigated during heating, whereby pure paraffin and the PCC sample were heated in a vacuum oven at $100{ }^{\circ} \mathrm{C}$ for $20 \mathrm{~min}$. Photographs were taken at 0,5 , and $20 \mathrm{~min}$ to compare the shape change of each sample. From the results in Figure 5, during paraffin heating, pure PCM cannot maintain its form, melting to liquid state, while the PCC maintained its shape and the liquid PCM largely remained in the PCC after melting, as numerous studies have reported previously [21,22]. The shape stability of carbon-based network structures can enhance the form-stability of PCCs. The stability of the carbon fiber network structure in the CFS can maintain the shape of the PCC during heating, and the micrometer-scale pores in the carbon fiber network possibly allow for capillary force to prevent PCM leakage.

Pure paraffin
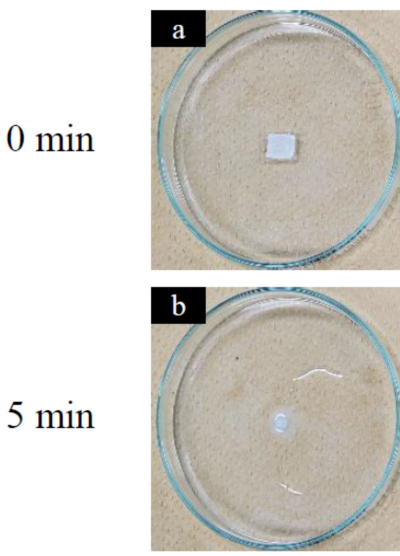

$5 \min$

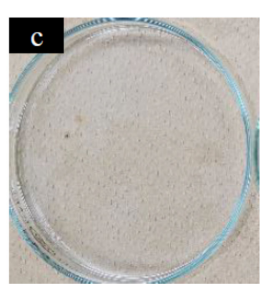

$20 \mathrm{~min}$
Par/CFS composite
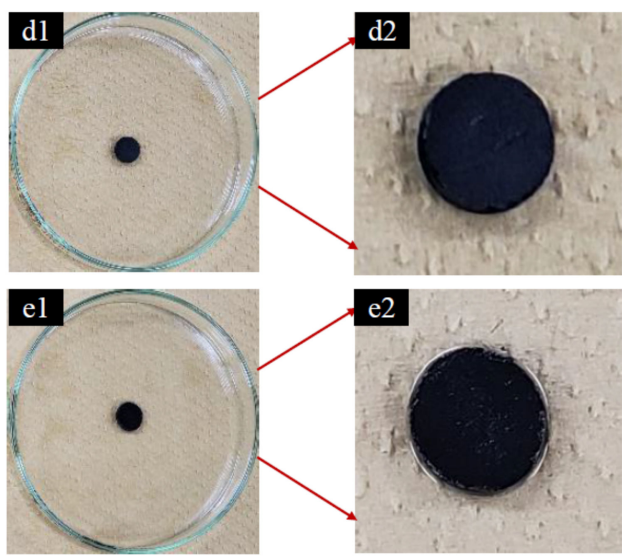

fl

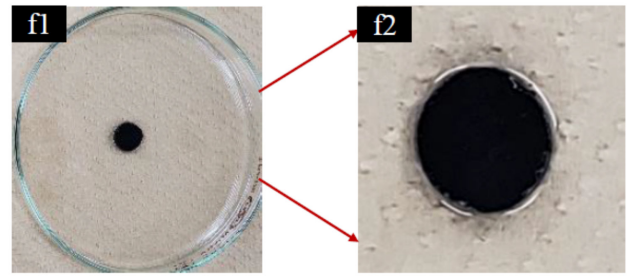

Figure 5. Leakage test result of pure paraffin and the PW/CFS composite. 
In summary, the PCC exhibited excellent durability for over 200 cycles and good shape-stability during heating and cooling. The results of the durability and shape-stability tests indicated that the carbon fiber network structure in the PCC remained stable during practical operation.

\subsection{Thermal Properties of the PCC}

The heat storage capacity of the PCC samples was measured by DSC, and Figure 6 depicts the DSC curves and heat storage capacities of the PCC before and after 20 and 200 thermal cycles. The thermal characteristics of each sample are shown in Table 2. The DSC curves resemble each other, and the melting point shifts for the PCM and PCC were minimal. The latent heat of pure paraffin during the melting process was $217.7 \mathrm{~J} \cdot \mathrm{g}^{-1}$ while that of the PCC before the durability test was $158.5 \mathrm{~J} \cdot \mathrm{g}^{-1}$, which is very close to the theoretical latent heat $\left(156.7 \mathrm{~J} \cdot \mathrm{g}^{-1}\right)$ calculated using the mass fraction of paraffin $(72 \%)$ in the PCC. This verifies that the latent heat of the paraffin PCM in the PCC was not affected by the addition of CFS, and there was no chemical reaction between paraffin and carbon fiber during impregnation. After the durability test, the melting latent heat of the PCC decreased to $147.67 \mathrm{~J} \cdot \mathrm{g}^{-1}$ ( 20 cycles) and $139.96 \mathrm{~J} \cdot \mathrm{g}^{-1}$ (200 cycles). The latent heat of the PCC remained at $88 \%$ of its original value after 200 thermal cycles. After the durability test, we noted that a small amount of PCM had leaked out and attached to the aluminum foil package. A comparison of the PCC weight before and after 200 cycles indicated a sample weight loss of approximately $12 \%$, which caused a reduction in the latent heat. For practical applications, a more compact packaged PCC unit should be formed to prevent the leakage of PCM more effectively. Nevertheless, the latent heat of the PCC remained stable after 200 cycles after eliminating the effect of PCM leakage, and latent heat degradation of the PCM did not occur.
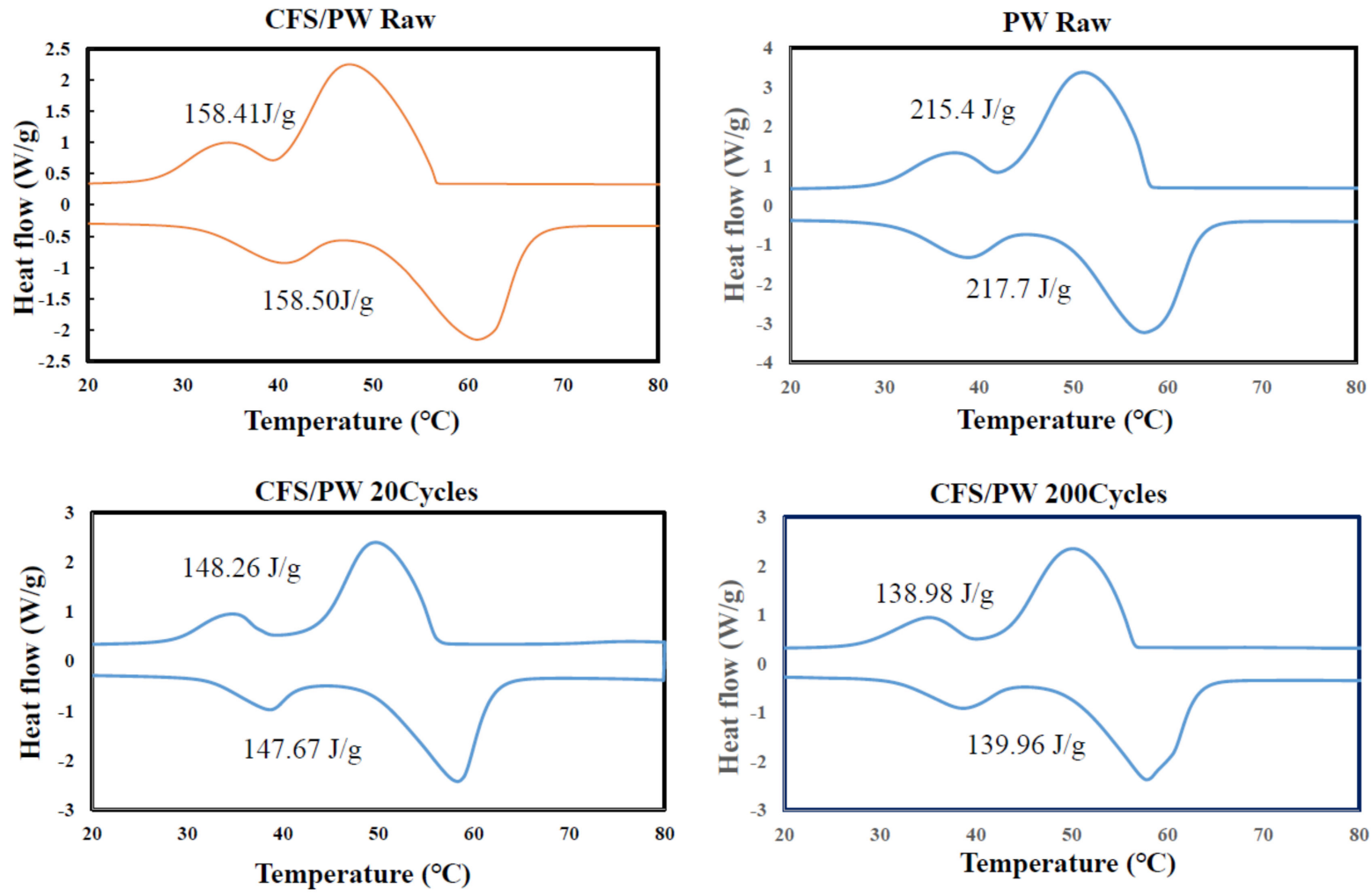

Figure 6. Thermal characteristics of paraffin wax phase change materials (PCM) and PW/CFS composite before and after durability test. 
Table 2. Thermal characteristics of PCM and PCC.

\begin{tabular}{ccccc}
\hline Specimen & $\begin{array}{c}\text { Melting Point } \\
(\mathbf{p e a k})\left[{ }^{\circ} \mathbf{C}\right]\end{array}$ & $\begin{array}{c}\text { Latent Heat } \\
(\mathbf{m})\left[\mathbf{k J} \cdot \mathbf{k g}^{-\mathbf{1}}\right]\end{array}$ & $\begin{array}{c}\text { Solidification } \\
\text { Point (peak) }\left[{ }^{\circ} \mathbf{C}\right]\end{array}$ & $\begin{array}{c}\text { Latent Heat (s) } \\
{\left[\mathbf{k J} \cdot \mathbf{k g}^{-\mathbf{1}}\right]}\end{array}$ \\
\hline PCM & 57.35 & 217.70 & 50.96 & 215.40 \\
\hline PCC & 60.54 & 158.50 & 47.24 & 158.41 \\
\hline PCC 20 cycles & 59.90 & 147.67 & 49.46 & 148.26 \\
\hline PCC 200 cycles & 57.58 & 139.96 & 50.09 & 138.98 \\
\hline
\end{tabular}

\subsection{Chemical Stability of the PCC}

The PCM is expected to be a chemically stable material during its heat storage and release process; therefore, investigating the enhancement of chemical stability of the PCC is crucial. The XRD patterns of pure paraffin, pure CFS, and the PCC before and after thermal cycling are shown in Figure 7. The CFS exhibited a carbon crystal peak at $26.6^{\circ}$ and one sub-peak; paraffin wax exhibited two major peaks at $21.8^{\circ}$ and $24.2^{\circ}$. All of these paraffin and CFS characteristic peaks can be detected in the PCC pattern before and after the durability test, and no additional peaks were detected. Combining the SEM images and thermal properties with the XRD results, it is evident that no chemical reaction had occurred during the fabrication and cyclic working process of the PCC. In the PCC, the CFS network and paraffin PCM are physically combined and the composite displayed favorable chemical stability during practical thermal cycles.

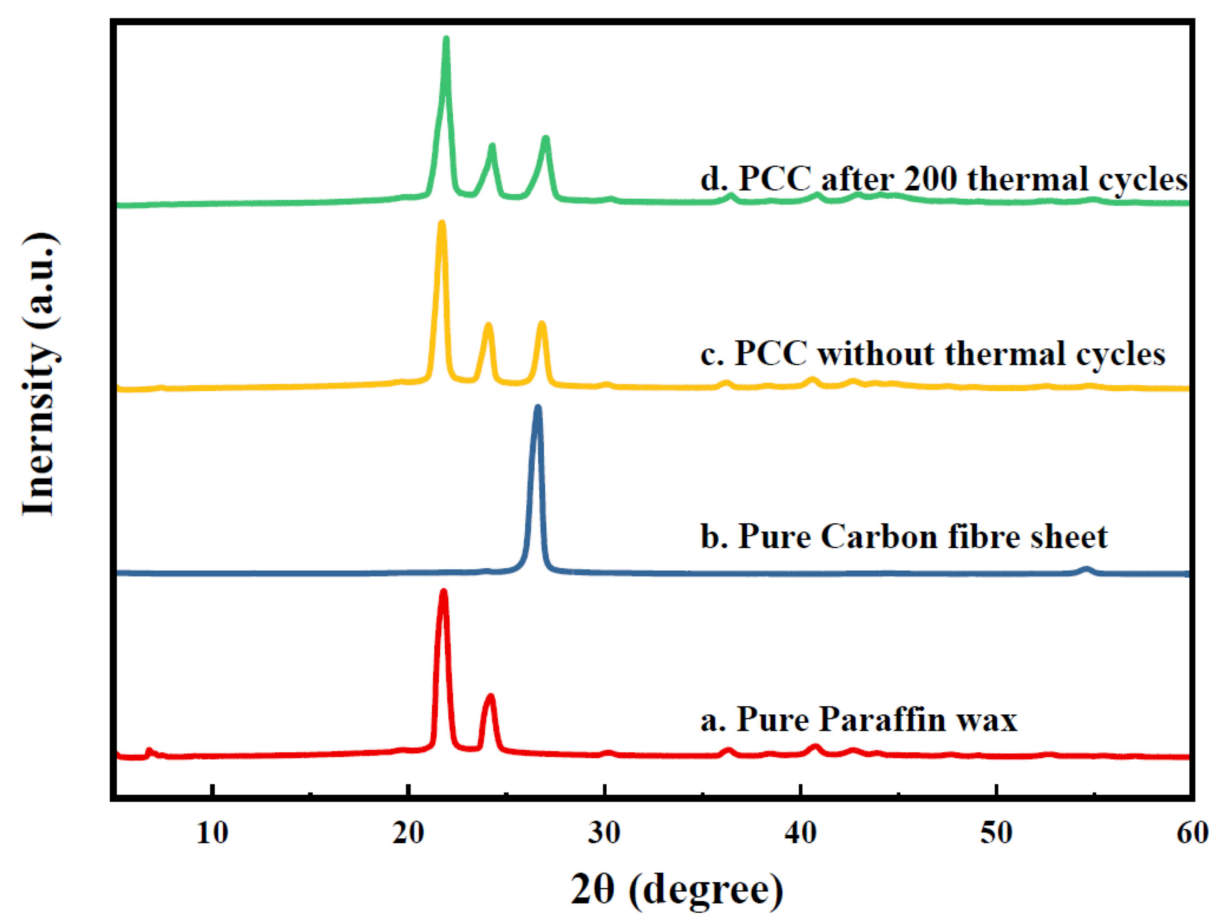

Figure 7. XRD patterns of (a) pure paraffin, (b) pure carbon fiber sheet, (c) PCC before thermal cycles and (d) PCC after 200 thermal cycles.

\section{Conclusions}

A new type of paraffin-wax-based latent heat storage composite material was successfully fabricated in this study. The thermal transfer performance, thermal storage performance, and microstructure of the PCC were investigated. The conclusions of this research can be summarized as follows:

1. The thermal conductivity of the PCM was enhanced from $0.24 \mathrm{~W} \cdot \mathrm{m}^{-1} \cdot \mathrm{K}^{-1}$ to $11.68 \mathrm{~W} \cdot \mathrm{m}^{-1} \cdot \mathrm{K}^{-1}(4670 \%)$ in the horizontal direction with a CFS content of $17.44 \%$. The PCC exhibited a strongly anisotropic high thermal conductivity in the horizontal direction. 
2. The PCC displayed good durability and shape stability; the thermal conductivity retention rate of the PCC was $85.9 \%$ and $78.6 \%$ after 20 and 200 thermal cycles, respectively. The composite also showed a good shape-stability and leakage-proof ability during the melting of PCM. The stability of the carbon fiber network structure in the CFS contributed to this favorable outcome.

3. The PCC proved to be chemically stable during fabrication and practical thermal cycling, as evident from the XRD results, which indicated only the physical combination between the CFS and paraffin.

4. The thermal characteristics of the PCM and PCC verify that the heat storage capacity and the heat storage/release temperature of the PCC remained stable and that the addition of the CFS did not have an effect on the heat storage capacity of the PCC. The latent heat of the PCC attained $158.50 \mathrm{~J} \cdot \mathrm{g}^{-1}$.

Author Contributions: K.D. performed all the experiments and wrote the manuscript. N.S. contributed significantly to the characterization and manuscript preparation. D.Z. contributed to perform the experiment and preparation of manuscript significantly. C.W. and X.Y. helped perform the analysis with constructive discussions. T.N. contributed to the concept of the study and supervised this research. All authors have read and agreed to the published version of the manuscript.

Funding: This research received no external funding.

Institutional Review Board Statement: Not applicable.

Informed Consent Statement: Not applicable.

Data Availability Statement: Data available in a publicly accessible repository.

Acknowledgments: The financial support provided by China Scholarship Council (CSC) during the doctoral stage of Kaixin Dong in Hokkaido University is acknowledged.

Conflicts of Interest: The authors declare no conflict of interest.

\section{References}

1. Gökgöz, F; Güvercin, M.T. Energy security and renewable energy efficiency in EU. Renew. Sustain. Energy Rev. 2018, 96, 226-239. [CrossRef]

2. Hasnain, S.M. Review on sustainable thermal energy storage technologies, Part I: Heat storage materials and techniques. Energy Convers. Manag. 1998, 39, 1127-1138. [CrossRef]

3. Sarı, A.; Bicer, A.; Al-Ahmed, A.; Al-Sulaiman, F.A.; Zahir, M.H.; Mohamed, S.A. Silica fume/capric acid-palmitic acid composite phase change material doped with CNTs for thermal energy storage. Sol. Energy Mater. Sol. Cells 2018, 179, 353-361. [CrossRef]

4. Fukai, J.; Hamada, Y.; Morozumi, Y.; Miyatake, O. Effect of carbon-fiber brushes on conductive heat transfer in phase change materials. Int. J. Heat Mass Transf. 2002, 45, 4781-4792. [CrossRef]

5. Xu, T.; Chen, Q.; Huang, G.; Zhang, Z.; Gao, X.; Lu, S. Preparation and thermal energy storage properties of d-Mannitol/expanded graphite composite phase change material. Sol. Energy Mater. Sol. Cells 2016, 155, 141-146. [CrossRef]

6. Zheng, H.; Wang, C.; Liu, Q.; Tian, Z.; Fan, X. Thermal performance of copper foam/paraffin composite phase change material. Energy Convers. Manag. 2018, 157, 372-381. [CrossRef]

7. Oya, T.; Nomura, T.; Tsubota, M.; Okinaka, N.; Akiyama, T. Thermal conductivity enhancement of erythritol as PCM by using graphite and nickel particles. Appl. Therm. Eng. 2013, 61, 825-828. [CrossRef]

8. Sheng, N.; Dong, K.; Zhu, C.; Akiyama, T.; Nomura, T. Thermal conductivity enhancement of erythritol phase change material with percolated aluminum filler. Mater. Chem. Phys. 2019, 229, 87-91. [CrossRef]

9. Wang, Z.; Zhang, Z.; Jia, L.; Yang, L. Paraffin and paraffin/aluminum foam composite phase change material heat storage experimental study based on thermal management of Li-ion battery. Appl. Therm. Eng. 2015, 78, 428-436. [CrossRef]

10. Fang, X.; Fan, L.W.; Ding, Q.; Yao, X.L.; Wu, Y.Y.; Hou, J.F.; Wang, X.; Yu, Z.T.; Cheng, G.H.; Hu, Y.C. Thermal energy storage performance of paraffin-based composite phase change materials filled with hexagonal boron nitride nanosheets. Energy Convers. Manag. 2014, 80, 103-109. [CrossRef]

11. Mohamed, N.H.; Soliman, F.S.; El Maghraby, H.; Moustfa, Y.M. Thermal conductivity enhancement of treated petroleum waxes, as phase change material, by $\alpha$ nano alumina: Energy storage. Renew. Sustain. Energy Rev. 2017, 70, 1052-1058. [CrossRef]

12. Chung, O.; Jeong, S.G.; Yu, S.; Kim, S. Thermal performance of organic PCMs/micronized silica composite for latent heat thermal energy storage. Energy Build. 2014, 70, 180-185. [CrossRef]

13. Burger, N.; Laachachi, A.; Ferriol, M.; Lutz, M.; Toniazzo, V.; Ruch, D. Review of thermal conductivity in composites: Mechanisms, parameters and theory. Prog. Polym. Sci. 2016, 61, 1-28. [CrossRef] 
14. Park, J.G.; Cheng, Q.; Lu, J.; Bao, J.; Li, S.; Tian, Y.; Liang, Z.; Zhang, C.; Wang, B. Thermal conductivity of MWCNT/epoxy composites: The effects of length, alignment and functionalization. Carbon 2012, 50, 2083-2090. [CrossRef]

15. Nomura, T.; Tabuchi, K.; Zhu, C.; Sheng, N.; Wang, S.; Akiyama, T. High thermal conductivity phase change composite with percolating carbon fiber network. Appl. Energy 2015, 154, 678-685. [CrossRef]

16. Yang, J.; Tang, L.S.; Bao, R.Y.; Bai, L.; Liu, Z.Y.; Xie, B.H.; Yang, M.B.; Yang, W. Hybrid network structure of boron nitride and graphene oxide in shape-stabilized composite phase change materials with enhanced thermal conductivity and light-to-electric energy conversion capability. Sol. Energy Mater. Sol. Cells 2018, 174, 56-64. [CrossRef]

17. Wang, T.; Wang, S.; Geng, L.; Fang, Y. Enhancement on thermal properties of paraffin/calcium carbonate phase change microcapsules with carbon network. Appl. Energy 2016, 179, 601-608. [CrossRef]

18. Heu, C.S.; Kim, S.W.; Lee, K.S.; Kim, D.R. Fabrication of three-dimensional metal-graphene network phase change composite for high thermal conductivity and suppressed subcooling phenomena. Energy Convers. Manag. 2017, 149, 608-615. [CrossRef]

19. Jiang, Z.; Ouyang, T.; Yang, Y.; Chen, L.; Fan, X.; Chen, Y.; Li, W.; Fei, Y. Thermal conductivity enhancement of phase change materials with form-stable carbon bonded carbon fiber network. Mater. Des. 2018, 143, 177-184. [CrossRef]

20. Sheng, N.; Zhu, R.; Dong, K.; Nomura, T.; Zhu, C.; Aoki, Y.; Habazaki, H.; Akiyama, T. Vertically aligned carbon fibers as supporting scaffolds for phase change composites with anisotropic thermal conductivity and good shape stability. J. Mater. Chem. A 2019, 7, 4394-4940. [CrossRef]

21. Qiu, J.; Fan, X.; Shi, Y.; Zhang, S.; Jin, X.; Wang, W.; Tang, B. PEG/3D graphene oxide network form-stable phase change materials with ultrahigh filler content. J. Mater. Chem. A 2019, 7, 21371-21377. [CrossRef]

22. Liu, Y.; Yang, Y. Form-stable phase change material based on $\mathrm{Na}_{2} \mathrm{CO}_{3} \cdot 10 \mathrm{H}_{2} \mathrm{O}-\mathrm{Na}_{2} \mathrm{HPO}_{4} \cdot 12 \mathrm{H}_{2} \mathrm{O}$ eutectic hydrated salt/expanded graphite oxide composite: The influence of chemical structures of expanded graphite oxide. Renew. Energy 2018, 115, 734-740. [CrossRef] 